\title{
Total synthesis of the indolizidine alkaloid tashiromine
}

\author{
Stephen P. Marsden ${ }^{*}$ and Alison D. McElhinney
}

\section{Full Research Paper}

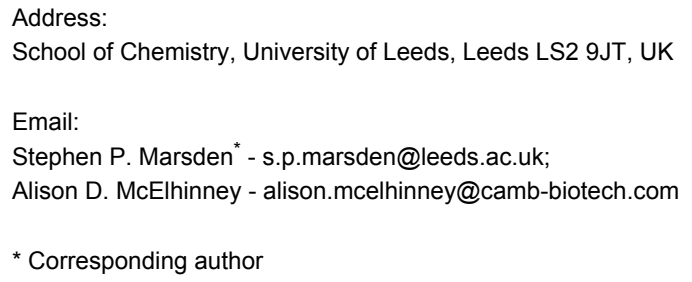

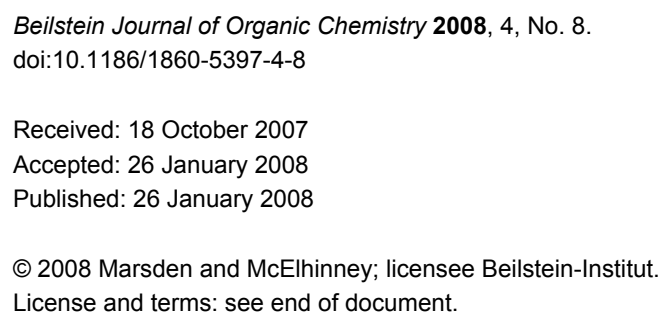

\begin{abstract}
\section{Background}

Tashiromine (1) is a naturally occurring indolizidine alkaloid. It has been the subject of thirteen successful total syntheses to date. Our own approach centres on the stereoselective construction of the indolizidine core by capture of an electrophilic acyliminium species by a pendant allylsilane. The key cyclisation precursor is constructed using olefin cross-metathesis chemistry, which has the potential to facilitate both racemic and asymmetric approaches, depending upon the choice of the allylsilane metathesis partner.
\end{abstract}

\section{Results}

The use of the allyltrimethylsilane cross-metathesis approach enables the rapid construction of the key cyclisation precursor 3 (3 steps from commercial materials), which undergoes acid-induced cyclisation to give the desired bicyclic indolizidine skeleton as a 96:4 mixture of diastereomers. Simple functional group interconversions allowed the completion of the total synthesis of racemic tashiromine in six steps (19\% overall yield). Three chiral $\alpha$-alkoxyallylsilanes $(\mathbf{1 2}, 14$ and 15) were prepared in enantioenriched form and their cross-metathesis reactions studied as part of a putative asymmetric approach to tashiromine. In the event, $\alpha$-hydroxysilane 12 underwent isomerisation under the reaction conditions to acylsilane 17, while silanes 14 and 15 were unreactive towards metathesis.

\section{Conclusion}

A concise, stereoselective total synthesis of racemic tashiromine has been developed. Attempts to translate this into an asymmetric synthesis have thus far been unsuccessful.

\section{Background}

Tashiromine (1) is a naturally occurring indolizidine, isolated from an Asian deciduous shrub Maackia tashiroi [1]. As one of the structurally simpler indolizidine alkaloids [2], tashiromine has been a popular target for synthetic chemists, and to date has succumbed to total synthesis on thirteen occasions [3-15]. A wide variety of reactions have been employed to assemble the 
core indolizidine structure, including radical cyclisations [3]; nucleophilic addition to imines $[5,14,15]$; electrophilic alkylation of pyrroles [7,13]; alkylation of enamines [6], $\beta$-amino esters [8] and pyrrolidinyllithiums [12]; stereoselective reduction of enamines [4,9] and pyridinium salts [11]; and titaniummediated reductive imide-olefin cyclisation [10]. Our own approach [14] utilises an intramolecular addition of an allylsilane to an $N$-acyliminium ion to deliver the [4.3.0]-azabicyclic (indolizidine) skeleton 2 (Scheme 1), wherein the pendant vinyl group acts as a handle to install the hydroxymethyl sidechain found in tashiromine. The synthesis of azabicyclic assemblies by intramolecular allylsilane $/ N$-acyliminium cyclisations was first studied by Hiemstra and Speckamp [16] who prepared their functionalised allylsilane cyclisation precursors (such as $\mathbf{3}$ ) by alkylation of cyclic imides with reagent $4(\mathrm{X}=\mathrm{OMs})$. This, in turn, was prepared in four steps by alkylation of an acetylide anion with commercially available iodomethyltrimethylsilane, followed by partial reduction of the alkyne. Alternative synthetic approaches to $4(\mathrm{X}=\mathrm{OMs}, \mathrm{I})$ involve olefination of aldehydes using the Seyferth-Fleming phosphorane [17] or nickel-catalysed 1,2-metallate rearrangement of lithiated dihydropyran [18]. Our approach was informed by the prior work by our own group [19-24] and others [25-38] on the use of olefin metathesis to generate functionalised allylsilanes. Specifically, cross-metathesis of $\mathrm{N}$-pentenylsuccinimide 5 with allyltrimethylsilane (6) [39] followed by chemoselective partial reduction of the imide would give the cyclisation precursor $\mathbf{3}$ in short order. Further, the use of chiral allylsilanes as cross-metathesis partners would potentially facilitate an asymmetric approach to the total synthesis of $\mathbf{1}$. We report herein full details of the successful synthesis of racemic tashiromine 1 by this strategy [14], as well as our initial attempts towards an asymmetric variant.

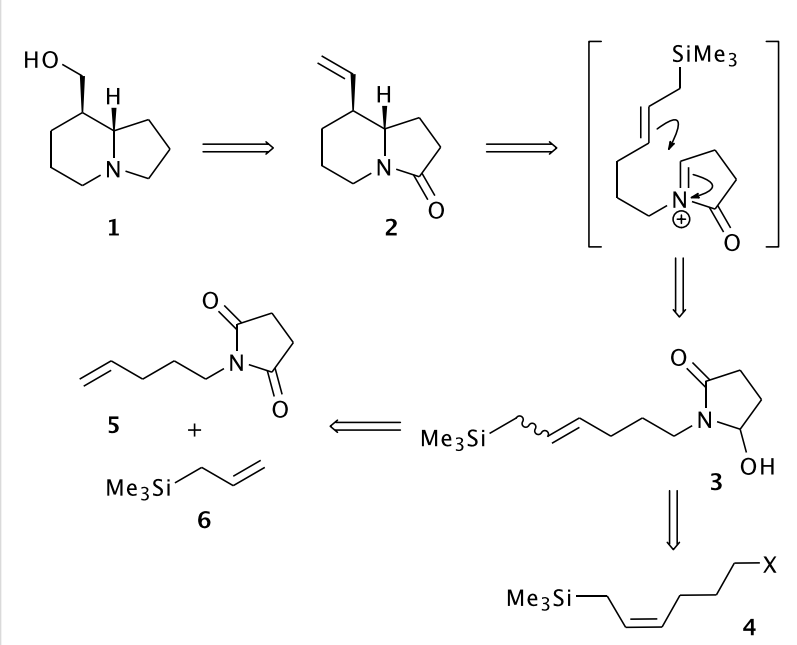

Scheme 1: Retrosynthesis for tashiromine.

\section{Results and Discussion}

Metathesis precursor 5 was prepared by alkylation of the sodium salt of succinimide with 5-bromo-1-pentene in near quantitative yield (Scheme 2, see Supporting Information File 1 for full experimental data). The key cross-metathesis reaction of 5 was carried out using a fourfold excess of allyltrimethylsilane (6) and $5 \mathrm{~mol} \%$ of Grubbs' second generation catalyst in refluxing dichloromethane. The desired product 7 was formed in $73 \%$ yield as an inseparable 3:1 mixture of $E$ - and $Z$-isomers. Partial reduction with sodium borohydride generated the cyclisation precursor 3 in $86 \%$ yield, again as a 3:1 mixture of olefin isomers. Exposure of this mixture to trifluoroacetic acid in dichloromethane at room temperature gave the bicyclic amide 2 in $85 \%$ yield as a $96: 4$ mixture of diastereomers. The identity of the major diastereomer was confirmed by comparison of the spectral data with those of Hiemstra [16]: specifically, the signal for the (ring-fusion) proton at $\mathrm{C} 6$ for the major diastereomer appeared as a doublet of triplets with $\delta=3.19$ ppm, whereas the corresponding signal for the minor diastereomer appeared at $\delta=3.67 \mathrm{ppm}$. The stereochemical outcome of this reaction was rationalised on the basis of the model shown in Scheme 2, whereby nucleophilic addition of the allylsilane to the $N$-acyliminium ion occurs through a chair-like transition state with the nascent alkene equatorially disposed.

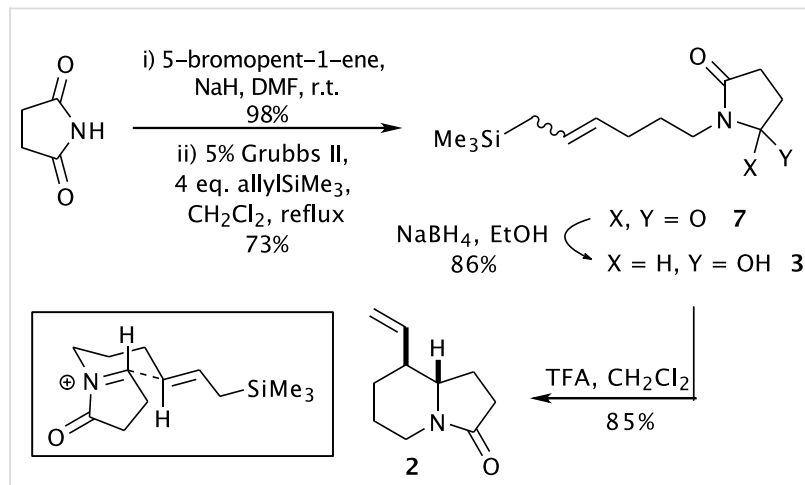

Scheme 2: Stereoselective construction of the indolizidine core 2.

All that remained to complete the synthesis of tashiromine $\mathbf{1}$ was to effect the oxidative cleavage of the C5 vinyl substituent, then carry out a global reduction of the resulting carbonyl function and the amide. In the event, attempts to form a C5 aldehyde using either ozonolytic or dihydroxylation/periodate alkene cleavage protocols were unsuccessful, with complex mixtures being obtained in both cases. We suspected that the problem lay in the potential for the desired aldehyde to undergo retro-Mannich fragmentation, and so elected to carry out a reductive work-up to the ozonolysis procedure (Scheme 3 ). The desired alcohol $\mathbf{8}$ was obtained in a crude form and immediately subjected to reduction with lithium aluminium hydride to 
give our target tashiromine $\mathbf{1}$ in 36\% yield over two steps. Our stereochemical assignment for the cyclisation of $\mathbf{3}$ was further corroborated by the agreement of the spectral data for $\mathbf{1}$ with those previously published in the literature [3-5,9-12]. Additionally, the spectral data for the diastereomeric epi-tashiromine have been reported and differ significantly from those recorded for 1 [10].

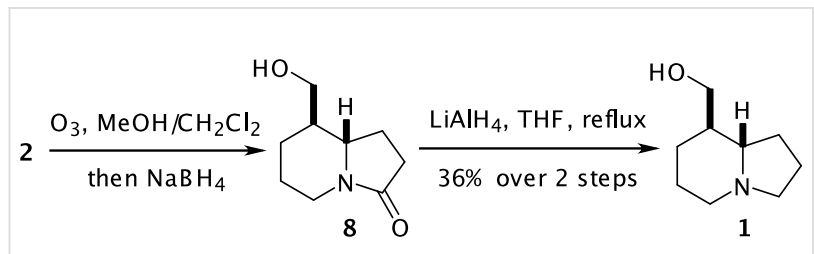

Scheme 3: Completion of the total synthesis of tashiromine 1.

Having completed our target synthesis, our next goal was to investigate an asymmetric approach to tashiromine. Specifically, we envisaged that cyclisation precursors of type 9 ought to be readily available by cross-metathesis of $\mathbf{5}$ with an appropriate chiral allylsilane followed by chemoselective partial reduction by borohydride. Thereafter, exposure to acid would generate an $\mathrm{N}$-acyliminium ion, which would cyclise through a chair-like transition state with the nascent alkenyl side-chain equatorially disposed, as in the racemic series (Figure 1). The absolute stereochemistry of the newly established asymmetric centres would be controlled by allylic strain arguments, assuming that the well-established precedent for anti- $\mathrm{S}_{\mathrm{E}} 2$, attack of the iminium on the allylsilane was upheld here [40]. Thus, the predicted major stereoisomer 10 would have $(5 S, 6 S)$ stereochemistry and an $E$-configured side-chain, while cyclisation to the predicted minor $(5 R, 6 R)$ isomer 11 would be disfavoured by $A_{1,3}$-interactions between the $\mathrm{R}^{1}$ group and vinylic proton (leading to the $Z$-configured side-chain). This would represent an immolative transfer of chirality approach to tashiromine, since the olefinic side-chains would be cleaved to install the hydroxymethyl side-chain required by the natural product.

Our approach centred on the readily availability of chiral $\alpha$-hydroxysilane 12 in enantioenriched format [41]. Protection of the hydroxyl group, either before or after cross-metathesis, would allow access to chiral allylsilanes 9 with $\mathrm{R}^{1}$ being an alkoxy or acyloxy group. Furthermore, this would generate products $\mathbf{1 0}$ and/or $\mathbf{1 1}$ with a readily oxidised enol-ether/ester side chain for progression to tashiromine. We were, of course, mindful that these functions could potentially act as nucleophiles themselves in the acidic medium of the electrophilic cyclisation, and the investigation of such chemoselectivity issues provided a further impetus for this study. Acylsilane $\mathbf{1 3}$ was therefore prepared from propargyl alcohol in four steps

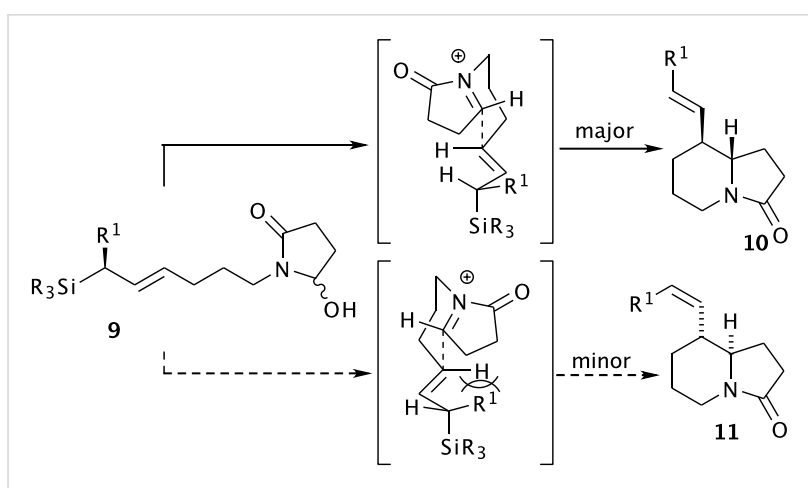

Figure 1: Rationale for stereoselective assembly of the indolizidine core using chiral allylsilanes.

then subjected to asymmetric reduction with (-)-DIPCl according to Buynak et al. (Scheme 4) [41]. The desired hydroxysilane 12 was obtained in 53\% yield and with $91 \%$ ee as determined by chiral HPLC analysis. Compound $\mathbf{1 2}$ was converted by standard methods to the acetate $\mathbf{1 4}$ and the tetrahydropyranyl ether $\mathbf{1 5}$. The latter compound was formed as a 1.3:1 mixture of diastereomers which were partially separated by column chromatography - all subsequent reactions were carried out on diastereomerically pure material for ease of analysis.

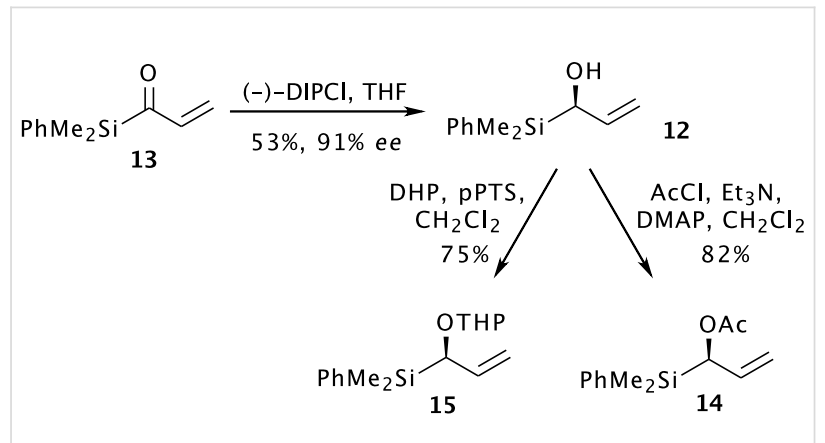

Scheme 4: Asymmetric synthesis of chiral (alkoxy)allylsilanes.

With the requisite enantioenriched allylsilanes in hand, we next investigated their behaviour in olefin cross-metathesis reactions. Unfortunately, neither $\mathbf{1 4}$ nor 15 reacted with 5 under the standard cross-metathesis conditions used for trimethylsilane $\mathbf{6}$; the use of more forcing conditions (elevated temperature and higher catalyst loadings) did not effect the desired transformation, the only product observed being that of homodimerisation of 5 (Scheme 5).

Finally, we examined the behaviour of alcohol 12 under crossmetathesis conditions. In the event, two isomerised products were isolated from this reaction (Scheme 6): the internal alkene 16 (formed in 99\% yield as a ca. 3:1 mixture of $E: Z$ isomers) 


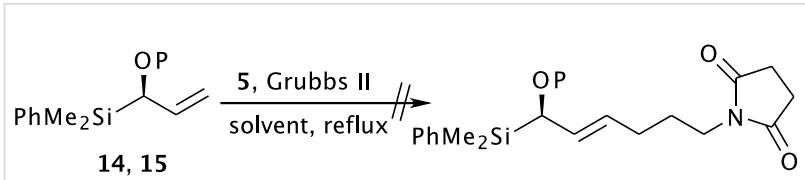

\begin{tabular}{cccc}
\multicolumn{2}{c}{ cat. loading } & solvent & outcome \\
14 & $5 \%$ & $\mathrm{CH}_{2} \mathrm{Cl}_{2}$ & no reaction \\
14 & $10 \%$ & $\mathrm{CH}_{2} \mathrm{Cl}_{2}$ & no reaction \\
14 & $20 \%$ & $\mathrm{CH}_{2} \mathrm{Cl}_{2}$ & no reaction \\
14 & $10 \%$ & toluene & no reaction \\
15 & $10 \%$ & $\mathrm{CH}_{2} \mathrm{Cl}_{2}$ & 5 homodimerises \\
15 & $10 \%$ & toluene & 5 homodimerises
\end{tabular}

Scheme 5: Attempted cross-metathesis of (alkoxy)allylsilanes.

and the acylsilane 17. The formation of isomerised alkenes accompanying (or instead of) metathesis processes using ruthenium-based catalysts is well documented [42-63], as is the formation of carbonyl compounds by isomerisation of the corresponding allylic alcohols [64-68]. At this stage we therefore reluctantly abandoned our investigations into the asymmetric synthesis of tashiromine.

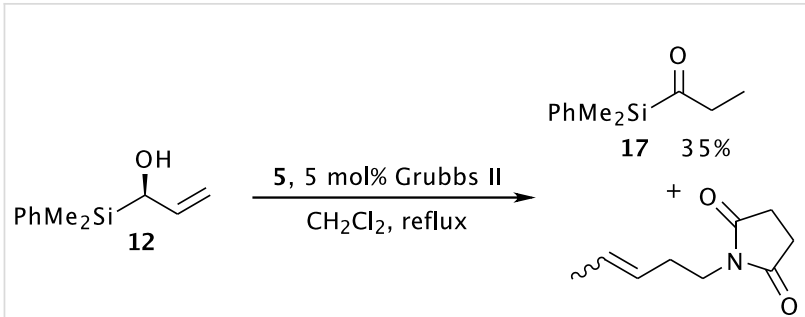

$1699 \%(3: 1 E: Z)$

Scheme 6: Competing isomerisation processes in attempted crossmetathesis of (hydroxy)allylsilane 12.

\section{Conclusion}

A concise, stereoselective total synthesis of racemic tashiromine has been developed (six steps from succinimide, 19\% overall yield) in which the key steps are the preparation of a functionalised allylsilane by olefin cross-metathesis and the construction of the indolizidine core by intramolecular addition of the allylsilane to an $\mathrm{N}$-acyliminium ion. Attempts to translate this into an asymmetric synthesis utilising cross-metathesis reactions of chiral $\alpha$-alkoxysilanes have thus far been unsuccessful.

\section{Experimental}

Experimental protocols for the synthesis of tashiromine $\mathbf{1}$ and the preparation of silanes $\mathbf{1 2}, \mathbf{1 4}, 15$ and 17 available as Supporting Information File 1.

\section{Supporting Information}

\section{Supporting Information File 1}

Supporting Information. Full experimental details and compound characterisation data for all new compounds described.

[http://www.beilstein-journals.org/bjoc/content/ supplementary/1860-5397-4-8-S1.pdf]

\section{Acknowledgments}

We thank the EPSRC for a studentship (ADM) and Pfizer and Merck for generous unrestricted research funding.

\section{References}

1. Ohmiya, S.; Kubo, H.; Otomasu, H.; Saito, K.; Murakoshi, I. Heterocycles 1990, 30, 537-542.

2. Michael, J. P. Nat. Prod. Rep. 2007, 24, 191-222. doi:10.1039/ b509525p

And references therein.

3. Beckwith, A. L. J.; Westwood, S. W. Tetrahedron 1989, 45, 5269-5282. doi:10.1016/S0040-4020(01)81101-7

4. Haddad, M.; Célérier, J. P.; Haviari, G.; Lhommet, G.; Dhimane, H.; Pommelet, J. C.; Chuche, J. Heterocycles 1990, 31, 1251-1260.

5. Nagao, Y.; Dai, W.-M.; Ochiai, M.; Tsukagoshi, S.; Fujita, E. J. Org Chem. 1990, 55, 1148-1156. doi:10.1021/jo00291a012

6. Paulvannan, K.; Stille, J. R. J. Org. Chem. 1994, 59, 1613-1620. doi:10.1021/jo00086a009

7. Gage, J. L.; Branchaud, B. P. Tetrahedron Lett. 1997, 38, 7007-7010. doi:10.1016/S0040-4039(97)01638-9

8. Ha, D.-C.; Park, S.-H.; Choi, K.-S.; Yun, C.-S. Bull. Korean Chem. Soc. 1998, 19, 728-730.

9. David, O.; Blot, J.; Bellec, C.; Fargeau-Bellassoued, M.-C.; Haviari, G.; Célérier, J.-P.; Lhommet, G.; Gramain, J.-C.; Gardette, D. J. Org. Chem. 1999, 64, 3122-3131. doi:10.1021/jo982169p

10. Kim, S.-H.; Kim, S.-I.; Lai, S.; Cha, J. K. J. Org. Chem. 1999, 64, 6771-6775. doi:10.1021/jo9907383

11. Bates, R. W.; Boonsombat, J. J. Chem. Soc., Perkin Trans. 1 2001, 654-656. doi:10.1039/b100407g

12. Dieter, R. K.; Watson, R. Tetrahedron Lett. 2002, 43, 7725-7728. doi:10.1016/S0040-4039(02)01835-X

13. Banwell, M. G.; Beck, D. A. S.; Smith, J. A. Org. Biomol. Chem. 2004, 2, 157-159. doi:10.1039/b312552a

14. McElhinney, A. D.; Marsden, S. P. Synlett 2005, 2528-2530. doi:10.1055/s-2005-917072

15. Bélanger, G.; Larouche-Gauthier, R.; Ménard, F.; Nantel, M.; Barabé, F. J. Org. Chem. 2006, 71, 704-712. doi:10.1021/jo052141v

16. Hiemstra, H.; Sno, M. H. A. M.; Vijn, R. J.; Speckamp, W. N. J. Org. Chem. 1985, 50, 4014-4020. doi:10.1021/jo00221a011

17. Paquette, L. A.; Mendez-Andino, J. L. J. Org. Chem. 1998, 63, 9061-9068. doi:10.1021/jo981683s

18. Bergmeier, S. C.; Seth, P. P. J. Org. Chem. 1997, 62, 2671-2674. doi:10.1021/jo962307f

19. Cassidy, J. H.; Marsden, S. P.; Stemp, G. Synlett 1997, 1411-1413. doi:10.1055/s-1997-1062

20. Miles, S. M.; Marsden, S. P.; Leatherbarrow, R. J.; Coates, W. J. J. Org. Chem. 2004, 69, 6874-6882. doi:10.1021/jo048971a 
21. Miles, S. M.; Marsden, S. P.; Leatherbarrow, R. J.; Coates, W. J. Chem. Commun. 2004, 2292-2293. doi:10.1039/b409528f

22. Akindele, T.; Marsden, S. P.; Cumming, J. G. Org. Lett. 2005, 7, 3685-3688. doi:10.1021/ol051292h

23. Akindele, T.; Marsden, S. P.; Cumming, J. G. Tetrahedron Lett. 2005, 46, 7235-7238. doi:10.1016/j.tetlet.2005.08.046

24. Cassidy, J. H.; Farthing, C. N.; Marsden, S. P.; Pedersen, A.; Slater, M.; Stemp, G. Org. Biomol. Chem. 2006, 4, 4118-4126. doi:10.1039/ b612256f

25. Teare, H.; Huguet, F.; Tredwell, M.; Thibaudeau, S.; Luthra, S. Gouverneur, V. ARKIVOC 2007, No. x, 232-244.

26. Thibaudeau, S.; Gouverneur, V. Org. Lett. 2003, 5, 4891-4893. doi:10.1021/ol035991a

27. Álvarez-Corral, M.; López-Sánchez, C.; Jiménez-González, L.; Rosales, A.; Muñoz-Dorado, M.; Rodríguez-García, I. Beilstein J. Org Chem. 2007, 3, No. 5. doi:10.1186/1860-5397-3-5

28. Jiménez-González, L.; García-Muñoz, S.; Álvarez-Corral, M.; MuñozDorado, M.; Rodríguez-García, I. Chem.-Eur. J. 2007, 13, 557-568. doi:10.1002/chem.200601017

29. Jiménez-González, L.; García-Muñoz, S.; Álvarez-Corral, M.; MuñozDorado, M.; Rodríguez-García, I. Chem.-Eur. J. 2006, 12, 8762-8769. doi:10.1002/chem.200600332

30. García-Muñoz, S.; Jiménez-González, L.; Álvarez-Corral, M.; MuñozDorado, M.; Rodríguez-García, I. Synlett 2005, 3011-3013. doi:10.1055/s-2005-921913

31. Jiménez-González, L.; Álvarez-Corral, M.; Muñoz-Dorado, M.; Rodríguez-García, I. Chem. Commun. 2005, 2689-2691. doi:10.1039/ b500919g

32. Vedrenne, E.; Dupont, H.; Oualef, S.; Elkaïm, L.; Grimaud, L. Synlett 2005, 670-672. doi:10.1055/s-2005-862375

33. He, A.; Yan, B.; Thanavaro, A.; Spilling, C. D.; Rath, N. P. J. Org. Chem. 2004, 69, 8643-8651. doi:10.1021/jo0490090

34. BouzBouz, S.; De Lemos, E.; Cossy, J. Adv. Synth. Catal. 2002, 344, 627-630. doi:10.1002/1615-4169(200208)344:6/7<627::AIDADSC627>3.0.CO;2-C

35. Meyer, C.; Cossy, J. Tetrahedron Lett. 1997, 38, 7861-7864 doi:10.1016/S0040-4039(97)10147-2

36. Taylor, R. E.; Engelhardt, F. C.; Schmitt, M. J.; Yuan, H. J. Am. Chem. Soc. 2001, 123, 2964-2969. doi:10.1021/ja0037163

37. Taylor, R. E.; Engelhardt, F. C.; Yuan, H. Org. Lett. 1999, 1, 1257-1260. doi:10.1021/ol990221d

38. Chang, S.; Grubbs, R. H. Tetrahedron Lett. 1997, 38, 4757-4760. doi:10.1016/S0040-4039(97)01031-9

39. Crowe, W. E.; Goldberg, D. R.; Zhang, Z. J. Tetrahedron Lett. 1996, 37, 2117-2120. doi:10.1016/0040-4039(96)00230-4

40. Fleming, I.; Barbero, A.; Walter, D. Chem. Rev. 1997, 97, 2063-2192. doi:10.1021/cr941074u

41. Buynak, J. D.; Strickland, J. B.; Lamb, G. W.; Khasnis, D.; Modi, S.; Williams, D.; Zhang, H. J. Org. Chem. 1991, 56, 7076-7083. doi:10.1021/jo00025a024

42. Miller, S. J.; Blackwell, H. E.; Grubbs, R. H. J. Am. Chem. Soc. 1996, 118, 9606-9614. doi:10.1021/ja961626l

43. Hoye, T. R.; Promo, M. A. Tetrahedron Lett. 1999, 40, 1429-1432. doi:10.1016/S0040-4039(98)02697-5

44. Maynard, H. D.; Grubbs, R. H. Tetrahedron Lett. 1999, 40, 4137-4140. doi:10.1016/S0040-4039(99)00726-1

45. Edwards, S. D.; Lewis, T.; Taylor, R. J. K. Tetrahedron Lett. 1999, 40, 4267-4270. doi:10.1016/S0040-4039(99)00703-0

46. Fürstner, A.; Thiel, O. R.; Ackermann, L.; Schanz, H. J.; Nolan, S. P. J. Org. Chem. 2000, 65, 2204-2207. doi:10.1021/jo9918504
47. Cadot, C.; Dalko, P. I.; Cossy, J. Tetrahedron Lett. 2002, 43, 1839-1841. doi:10.1016/S0040-4039(02)00141-7

48. Arisawa, M.; Terada, Y.; Nakagawa, M.; Nishida, A. Angew. Chem., Int. Ed. 2002, 41, 4732-4734. doi:10.1002/anie.200290031

49. Sutton, A. E.; Seigal, B. A.; Finnegan, D. F.; Snapper, M. L. J. Am. Chem. Soc. 2002, 124, 13390-13391. doi:10.1021/ja028044q

50. Wipf, P.; Rector, S. R.; Takahashi, H. J. Am. Chem. Soc. 2002, 124, 14848-14849. doi:10.1021/ja028603t

51. Schmidt, B. Eur. J. Org. Chem. 2003, 816-819. doi:10.1002/ ejoc. 200390124

52. Sworen, J. C.; Pawlow, J. H.; Case, W.; Lever, J.; Wagener, K. B. J. Mol. Catal. A 2003, 194, 69-78. doi:10.1016/S1381-1169(02)00524-1

53. Lehman, S. E., Jr.; Schwendeman, J. E.; O'Donnell, P. M.; Wagener, K. B. Inorg. Chim. Acta 2003, 345, 190-198. doi:10.1016/S00201693(02)01307-5

54. Peczuh, M. W.; Snyder, N. L. Tetrahedron Lett. 2003, 44, 4057-4061. doi:10.1016/S0040-4039(03)00849-9

55. Alcaide, B.; Almendros, P.; Alonso, J. M. Chem.-Eur. J. 2003, 9 , 5793-5799. doi:10.1002/chem.200305236

56. Kotha, S.; Mandal, K. Tetrahedron Lett. 2004, 45, 1391-1394. doi:10.1016/j.tetlet.2003.12.075

57. Schmidt, B. J. Org. Chem. 2004, 69, 7672-7687. doi:10.1021/ jo048937w

58. Hong, S. H.; Sanders, D. P.; Lee, C. W.; Grubbs, R. H. J. Am. Chem. Soc. 2005, 127, 17160-17161. doi:10.1021/ja052939w

59. Bennasar, M. L.; Roca, T.; Monerris, M.; García-Díaz, D. J. Org. Chem. 2006, 71, 7028-7034. doi:10.1021/jo061180j

60. Hanessian, S.; Giroux, S.; Larsson, A. Org. Lett. 2006, 8, 5481-5484. doi:10.1021/ol062167o

61. Courchay, F. C.; Sworen, J. C.; Ghiviriga, I.; Abboud, K. A.; Wagener, K. B. Organometallics 2006, 25, 6074-6086. doi:10.1021/om0509894

62. Raju, R.; Allen, L. J.; Le, T.; Taylor, C. D.; Howell, A. R. Org. Lett. 2007, 9, 1699-1701. doi:10.1021/ol070574+

63. Moïse, J.; Arseniyadis, S.; Cossy, J. Org. Lett. 2007, 9, 1695-1698. doi:10.1021/ol0703940

64. Gurjar, M. K.; Yakambram, P. Tetrahedron Lett. 2001, 42, 3633-3636. doi:10.1016/S0040-4039(01)00449-X

65. Greenwood, E. S.; Parsons, P. J.; Young, M. J. Synth. Commun. 2003, 33, 223-228. doi:10.1081/SCC-120015704

66. Werner, H.; Grünwald, C.; Stüer, W.; Wolf, J. Organometallics 2003, 22, 1558-1560. doi:10.1021/om0210006

67. Edlin, C. D.; Faulkner, J.; Fengas, D.; Knight, C. K.; Parker, J.; Preece, I.; Quayle, P.; Richards, S. N. Synlett 2005, 572-576. doi:10.1055/s2005-862384

68. Finnegan, D.; Seigal, B. A.; Snapper, M. L. Org. Lett. 2006, 8, 2603-2606. doi:10.1021/ol060918g 


\section{License and Terms}

This is an Open Access article under the terms of the Creative Commons Attribution License

(http://creativecommons.org/licenses/by/2.0), which permits unrestricted use, distribution, and reproduction in any medium, provided the original work is properly cited.

The license is subject to the Beilstein Journal of Organic Chemistry terms and conditions:

(http://www.beilstein-journals.org/bjoc)

The definitive version of this article is the electronic one which can be found at:

doi:10.1186/1860-5397-4-8 